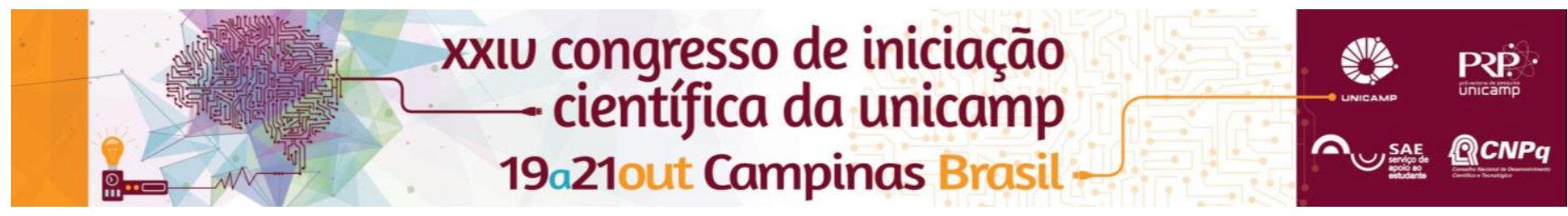

\title{
Avaliação Da Qualidade Dos Tratamentos Endodônticos: Estudo Retrospectivo Utilizando Imagens De Tomografia Computadorizada De Feixe Cônico
}

\author{
Maria Fernanda A. Silva*, Eduarda H. L. Nascimento, Deborah Q. Freitas
}

\section{Resumo}

Este estudo avaliou a qualidade dos tratamentos endodônticos, para detectar as principais falhas e dentes acometidos, e associá-la com as condições periapicais e radiculares, utilizando tomografia computadorizada de feixe cônico.

\section{Palavras-chave:}

Endodontia, Falha de tratamento, Tomografia computadorizada de feixe cônico.

\section{Introdução}

Tratamentos endodônticos são realizados frente ao quadro de injúria pulpar e têm o objetivo de eliminar os agentes agressores aos tecidos radiculares e periapicais, restabelecer a saúde e manter o dente em função. Porém, a alta complexidade dos canais radiculares e fatores como a resistência microbiana, aliados a possíveis falhas durante a realização dos procedimentos. O objetivo neste trabalho foi avaliar a qualidade dos tratamentos endodônticos e correlacioná-la com as condições dos tecidos periapicais e estrutura radicular, por meio de imagens de tomografia computadorizada de feixe cônico (TCFC). Além disso, objetivou-se detectar as causas mais prevalentes do insucesso em tratamentos endodônticos e quais os dentes mais envolvidos nesses casos.

\section{Resultados e Discussão}

Considerando os 1061 canais radiculares avaliados, 641 $(60,4 \%)$ apresentaram obturações adequadas e 420 $(39,6 \%)$ apresentaram algum tipo de falha. Foi encontrada uma associação estatisticamente significante entre os tratamentos endodônticos inadequados e a presença lesões periapicais $(p<0.0001)$ (Tabela 1). No entanto, não houve diferenças entre a qualidade do tratamento endodôntico e a presença ou ausência de reabsorções radiculares, seja do tipo interna ou externa $(p>0.05)$. O motivo mais prevalente de falha no tratamento endodôntico foi a obturação aquém do ápice radicular, presente em quase metade dos casos $(49,2 \%)$, seguida pela restauração coronária defeituosa $(16,4 \%)$ e pela obturação não homogênea $(11,4 \%)$. Sabe-se que a complexidade anatômica do sistema de canais radiculares é muitas vezes responsável pelo insucesso no tratamento endodôntico, ou ainda devido à presença de microrganismos resistentes aos medicamentos utilizados no procedimento. No entanto, o insucesso pode ocorrer devido a falhas do cirurgião dentista durante as fases do tratamento. Estudos afirmaram que a presença de restauração coronária e a extensão apical ideal do preenchimento do canal radicular foram significativamente associadas com tecidos apicais saudáveis. Já o preenchimento insatisfatório do canal não foi considerado um fator determinante para o insucesso do tratamento endodôntico, mesmo tendo a presença de tecido necrótico inflamatório e bactérias nesses espaços; acredita-se tratar apenas de um fator contribuinte. ${ }^{1}$
Figura 1. Imagens de TCFC mostrando exemplos de falhas em tratamentos endodôticos.

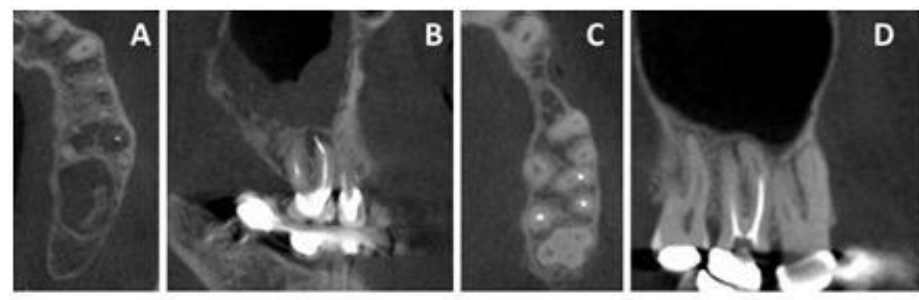

A e B - Obturação além do ápice radicular; C - Canal não obturado; D - Obturação aquém do ápice radicular.

Tabela 1. Associação entre a qualidade dos tratamentos endodônticos e a presença ou ausência de lesões periapicais e reabsorção radicular (externa e interna)

\begin{tabular}{|c|c|c|c|c|}
\hline \multirow[t]{2}{*}{ Variáveis } & \multicolumn{2}{|c|}{$\begin{array}{c}\text { Qualidade do } \\
\text { tratamento endodontico } \\
\mathrm{n}(\%)\end{array}$} & \multirow[t]{2}{*}{ OR } & \multirow[t]{2}{*}{ p-valor } \\
\hline & Adequado & Inadequado & & \\
\hline \multicolumn{5}{|l|}{$\begin{array}{l}\text { Lesão } \\
\text { periapical }\end{array}$} \\
\hline Presente & $273(42,6)$ & $290(69)$ & 3.0 & $<0.0001$ \\
\hline Ausente & $368(57,4)$ & $130(31)$ & 1 & \\
\hline \multicolumn{5}{|c|}{ Reabs. externa } \\
\hline Presente & $17(2,7)$ & $18(4,3)$ & 1.64 & 0.2001 \\
\hline Ausente & $624(97,3)$ & $402(95,7)$ & 1 & \\
\hline \multicolumn{5}{|c|}{ Reabs. interna } \\
\hline Presente & $3(0.5)$ & $7(1,7)$ & 3.6 & 0.0987 \\
\hline Ausente & $638(99.5)$ & $413(98,3)$ & 1 & \\
\hline $\begin{array}{l}\text { TOTAL } \\
(n=1061)\end{array}$ & $641(60,4)$ & $420(39,6)$ & & \\
\hline
\end{tabular}

\section{Conclusões}

A qualidade do tratamento endodôntico tem grande influência na presença ou ausência de lesões periapicais, interferindo diretamente no prognóstico do caso. No entanto, não interfere na presença de reabsorções internas ou externas na raiz.

\section{Agradecimentos}

Ao Conselho Nacional de Desenvolvimento Científico e Tecnológico (CNPq) e ao Programa Institucional de Bolsas de Iniciação Científica (PIBIC).

1 - Venskutonis T, et al., Periapical and Endodontic Status Scale Based on Periapical Bone Lesions and Endodontic Treatment Quality Evaluation Using Cone-beam Computed Tomography. J Endod. 2015;41(2): 190-6. 